Article

\title{
An Integrated Methodology for the Multi-Objective Optimization of Port Railway Capacity: The Case Study of the Port of Trieste
}

\author{
Caterina Caramuta ${ }^{1, *(D)}$, Giovanni Longo ${ }^{1}$, Teresa Montrone ${ }^{2}$ and Carlo Poloni ${ }^{1}$ \\ 1 Department of Engineering and Architecture, University of Trieste, 34127 Trieste, Italy; \\ giovanni.longo@dia.units.it (G.L.); poloni@units.it (C.P.) \\ 2 Esteco S.p.A, 34149 Trieste, Italy; montrone@esteco.com \\ * Correspondence: caterina.caramuta@phd.units.it; Tel.: +39-040-558-35-73
}

Citation: Caramuta, C.; Longo, G.;

Montrone, T.; Poloni, C. An

Integrated Methodology for the

Multi-Objective Optimization of Port Railway Capacity: The Case Study of the Port of Trieste. Sustainability 2021, 13, 10490. https://doi.org/10.3390/ su131910490

Academic Editor: Aoife Ahern

Received: 5 August 2021

Accepted: 17 September 2021

Published: 22 September 2021

Publisher's Note: MDPI stays neutral with regard to jurisdictional claims in published maps and institutional affiliations.

Copyright: (C) 2021 by the authors. Licensee MDPI, Basel, Switzerland. This article is an open access article distributed under the terms and conditions of the Creative Commons Attribution (CC BY) license (https:/ / creativecommons.org/licenses/by/ $4.0 /)$.

\begin{abstract}
The relevant pressure exerted on ports following the advent of globalization and containerization has contributed to transform the role of such intermodal transport facilities, increasing their complexity with reference to both performed activities and involved actors. The potential of solid hinterland connections in enhancing port competitiveness has sustained the larger embracement of the railway mode, which has proved to be a financially and environmentally sustainable solution, especially on long hauls. However, the limited residual capacity currently characterizing several railway network and nodes may threaten the accommodation of additional future traffic volumes and, thus, it requires the adoption of a coordinated strategy to more efficiently manage existing railway infrastructures, other than the realization of some new ones. In this regard, an integrated methodology has been developed to specifically model, simulate and optimize port railway processes, as part of a more complex system, imposing the maximization of capacity with the concurrent minimization of used shunting locomotives, to varying of infrastructural and operational conditions. This combination of techniques has been applied to the case study of the Port of Trieste, Italy, showing the greater influence of tracks availability over changes in the operational conditions, in terms of a shorter duration of specific administrative tasks and the employment of more shunting locomotives.
\end{abstract}

Keywords: intermodal systems; port; railway capacity; optimization

\section{Introduction}

Major developments in trade exchanges generated by globalization and containerization have enhanced the role of seaports, transforming them from conventional intermodal interfaces to active components of the global distribution channel [1]. The complexity of such transport systems has consequently increased due to the performing of a larger variety of activities, which have entailed the engagement of multiple actors. In face of that, the provision of an augmented offer including both maritime and logistics services has permitted them to meet the ever-demanding needs of port customers, conferring an added value to port operations [2,3]. The adoption of containerized transfer units has certainly brought to light the importance of establishing solid hinterland connections, extending the potential catchment area of ports and, thus, raising the competitiveness among them [4]. In this regard, driven mainly by the urgency of addressing environmental issues, ports are intended to embrace intermodality even more in the future, especially with reference to the railway mode. Moreover, this transport solution demonstrates to be more financially sustainable on long hauls, compared against the road mode [5]. Such tendency is perfectly in line with the solutions proposed in a few Communications of the European Commission to address the wider problem of strengthening the port-city relationship, in face of the increasing international traffic demand at ports. According to these documents, the establishment of sustainable inland connections, in terms of itineraries and transport modes, and an efficient control of port accesses would contribute to guarantee an environmental 
safeguard and citizens' safety, while turning ports into facilitators for multimodality and growth $[6,7]$. However, the expected growth in freight railway traffic is largely challenged by the quite limited residual capacity which currently characterizes railway networks in many countries. Therefore, given also the long-lasting procedures for the realization of infrastructural interventions, a prompt and coordinated action by part of the main involved stakeholders is vital to define the most adequate strategy to overcome such physical barrier. Furthermore, the actualization of organizational and technological initiatives is necessary to enable a more efficient usage of existing capacity, possibly leading to a seamless transfer of goods not only inside ports, but along the whole transport chain [8].

In light of the articulation of port systems and their pressing need of accommodating future additional traffic flows, the objective of the present paper consists of delivering a methodology for the optimization of port railway capacity. The innovation of the methodology is represented by the integration of different consolidated techniques to be applied in the various implementation stages, allowing an effective and comprehensive examination of the problem at hand. In more detail, the proposed methodology first considers the modelling of railway processes, in order to facilitate the analysis of their execution and, thus, to suggest possible hindering factors. In analogy with the industrial sector, railway processes are graphically displayed using a standardized modelling language generally employed for business processes, which enables the exchange of process models with tools dedicated to parametrization and simulation. The former serve the function of setting the entity of represented elements in different simulation scenarios, which correspond to diverse operational conditions both at infrastructural and operational level. The latter, adopting a discrete-event approach, allows efficiently identifying process bottlenecks, highlighting the aspects on which interventions are required to improve railway capacity. Finally, process optimization assists the estimation of the maximum annual number of trains, when changing some input variables related to infrastructural resources and operational features. The validity of the suggested methodology has been proven by its application to the case study of the Port of Trieste, Italy, for which the discussion of results is presented.

The paper is structured as follows. Section 2 contains a detailed explanation of the implementation phases of the proposed methodology and a literature review which has been carried out in relation to the main objective of developed approach, whose application to the case study is described in Section 3. Results have been reported and analyzed in Section 4, highlighting the practical implications to be delivered to port decision makers. Conclusions and future advancements of the research presented in this paper are included in Section 5, stressing the most significant features of the investigation and its potential transferability to other contexts.

\section{Materials and Methods}

The combination of methods and techniques used in the proposed methodology underlines the complexity of accomplishing the estimation of the maximum port railway capacity due to the multiplicity of aspects to be considered. A schematic representation of the implementation phases of the proposed methodology is reported in the form of workflow in Figure 1.

In the followings each stage is explained in detail and discussed in strict relation to the objective of the suggested methodology, i.e., the optimization of port railway processes for the estimation of the respective capacity, overlooking side issues influencing port potential such as terminal operations efficiency, pricing policies or the relation with dry ports. These latter topics are of course crucial in any port planning and development activity on a macroscopic level of analysis but, according to a more detailed perspective, further specific issues (as the one considered in this paper) may affect port performances with relevant environmental effects. 


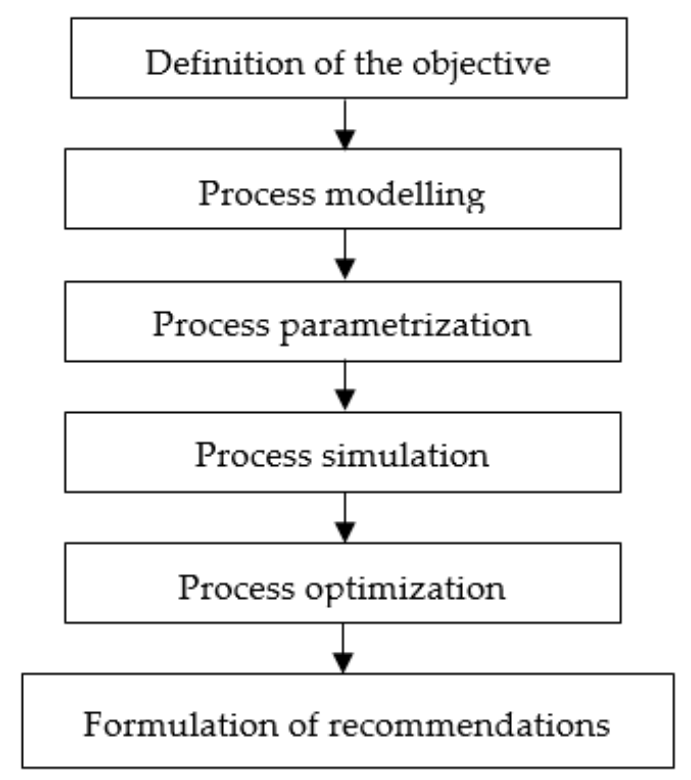

Figure 1. Workflow of the implementation phases of the suggested methodology.

First of all, in analogy with the Business Process Management (BPM) strategies adopted in product industries, railway processes have been displayed by means of a standardized modelling language, highlighting the relevance of the organizational issues that characterize intermodal transport operations. Indeed, together with execution and interchange standards, graphical standards represent one of the BPM techniques for the process design and enactment phases of the BPM life cycle and allow users to express process features in a diagrammatic way [9]. Both current ("as is") and future ("to be") configurations of the considered business processes can be captured when developing models, assisting the performing of a gap analysis to determine possible process improvements [10]. To this end, BPM requires the support of software solutions able to facilitate process analysis through the creation of intuitive process models, which can serve the purposes of various stakeholders [11]. With reference to the transport and logistics sector, the increasing implementation of a process-oriented approach has boosted the search for efficient instruments for process modelling and analysis, leading to the creation of numerous modelling methods and corresponding IT alternatives [12]. Among the most widespread business process modelling techniques, i.e., the Unified Modelling Language Activity Diagrams (UML AD), the Event-driven Process Chains (EPC) and the Role-Activity Diagrams (RADs) [9], the Business Process Model and Notation (BPMN) represents the de facto standard to model business processes, whose Specification document is provided by the Object Management Group [13]. BPMN consists of a standardized modelling language which combines visualization with a rigorous XML encoding of processes by translating each graphical element, such as tasks, gateways and events, into the corresponding XML one. By including the technical details necessary for process execution, BPMN models can be deployed not only to communicate and interchange the requirements of business processes, but also to execute them on enterprise engines. This latter functionality constitutes one of the main reasons for the selection of BPMN to model railway processes in this paper, together with its capability of displaying business processes at different levels of granularity. Process modelling has been carried out using the online editor called Cardanit, which is developed by Esteco S.p.A. [14]. In particular, on one hand, great effort has been put to attain model understandability and, on the other hand, key stakeholders have been involved with the aim of building context-sensitive models. With regard to process modelling, in line with the scope of the paper, the literature analysis has been limited to scientific contributions adopting both the BPMN standard and a holistic perspective of port system topics, rather than those focusing on specific maritime-related issues. The aspects of intermodality and port logistics faced in some of those articles relate mainly to 
information flows between the involved actors, underlining its relevant effect to smooth freight transfers. For instance, given the impact of communication on the potential increase in the customer value of port logistics processes, in [15] activities, events and IT systems referring to the incoming container traffic via the port of Hamburg have been modelled using BPMN. Investigations on the created models have been then carried out with respect to standardization and integration, in order to identify which significant junctures in the transport chain would benefit from a seamless information exchange, entailing an improvement in the utilization of existing infrastructures. In [16], the Port Community System (PCS) of Salerno, Italy, has been thoroughly examined thanks to the development of BPMN models, considering not only the organizational procedure of each engaged actor, but also the inter-organizational routines between them. Referring to the administrative activities of an export process, the status quo of port logistics operations and their future configuration have been visualized to evaluate possible advancements in process reliability and efficiency. A compared analysis of current and potential performances of the PCS has been performed to outline a transition plan which would enable the execution of intelligent logistics services.

The simulation of railway processes has been carried out through Discrete Event Simulation (DES), since it constitutes the most appropriate approach to animate the processes unfolding in transport systems, intended as networks of queues and servers [17]. Process simulation has served the estimation of port railway capacity at strategic level and the identification of potential bottlenecks, as a result of the analysis of infrastructure utilization and the development of what-if scenarios [18]. As far as available DES instruments are concerned, a simulation tool based on business process modelling notation has been preferred over simulation packages, due to their main disadvantage of providing proprietary building blocks which complicate the exchange of simulation models between packages [19]. Initial simulation results have been deployed to calibrate and validate the developed models following their parametrization phase, with the aim of ensuring that they properly reflect the actual performing of the examined railway operations. The properties of modelled elements and of the simulation scenario have been set using the BPSim (Business Process Simulation) standard, which has been developed by the Workflow Management Coalition. It defines a specification for the parametrization and interchange of process analysis data, permitting augmenting BPMN models with process information. In this regard, one of the main objectives of the BPSim specification consists exactly in being complementary to already existing languages for business process modelling. The specification is composed by a meta-model, consisting of an underlying computer-interpretable representation, and by an interchange format, which is a coupled electronic file format for the protection and transfer of data between different instruments. The former is captured through the UML standard, whereas the latter is defined via an XML Schema Definition (XSD) [20]. For simulation purposes, a technology developed by the Lanner Group, called L-Sim, has been adopted [21]: it is formed by a comprehensive standard-based simulation engine which supports the BPMN 2.0 Interchange format and the BPSim standard. L-Sim offers a variety of structured statistical outcomes which allow the identification of the best KPIs (Key Performance Indicators), other than facilitating effective process design and the prioritization of investments. Referring to the port logistics sector, the related literature shows that the majority of modern simulation studies have been elaborated using the BPMN standard, such as, for example, the one reported in [22], where BPMN modelling and simulation has been functional to the assessment of possible process enhancements generated by the adoption of smart Information and Communication Technologies on a maritime container terminal in the Port of Leghorn, Italy. Such appraisal has been carried out with respect to the dwell time of cargo in the port, with the aim of determining future process configurations to strengthen port efficiency through a better integration of the land and sea segments. Two further attempts of converting graphical models into simulation processes have been performed in $[23,24]$, integrating BPMN formalism, respectively, with Petri-Nets and the Complex Event Processing (CEP) engines. In the first case, logistics 
processes in the multimodal transport chain from Hong Kong to Narvik, through Shanghai and Rotterdam, have been simulated considering both the involved transport nodes and their connections, with reference to the mean transfer time of containers. In the second case, the real scenario of an intermodal logistics chain from Austria to Romania has been modelled and animated in order to monitor, on one side, the collaboration among resources and, on the other side, the occurrence of expected and unexpected events in a complex logistics process.

The resorting to multi-objective optimization approaches has proved to be particularly useful when facing real-life design problems, because they allow taking account of different and usually conflicting goals, also in cases where the obtainable compromise level is not known a priori [25]. In this paper, the optimization procedure has been performed by means of a Multi-Disciplinary Optimization (MDO) framework, which permits setting the details of engineering design processes through an intuitive workflow. By including both the logical steps of the process and the relative input and output variables, such MDO framework is able to combine the Data Flow with the Process Flow. The former considers the transfer of data between the different steps of the process, while the latter encompasses the consequent actions to be undertaken and the conditions to be evaluated. The presence in the MDO framework of specific nodes acting as a Black Box allows the integration with external tools and thus the computation of the output variables, according to the input variables defined for the engineering design process. The Black Box can contain different computational elements, such as a calculator, a script, or a specific external procedure or tool, such as Computer-Aided Engineering (CAE), Computer-Aided Design (CAD) and Finite Element Methods (FEM) tools [26]. In particular, the MDO framework adopted in the proposed methodology consists of the multi-disciplinary software called modeFRONTIER (mF), which has been developed by Esteco S.p.A. [27]. Some of the iterative optimization algorithms for single- and multi-objective optimization problems included in the $\mathrm{mF}$ framework belong to the family of Genetic Algorithms (GAs), which have been first developed by Holland in the 1970s [28]. Through a probabilistic approach, in the reproduction process the recombination of the good characteristics coming from each parent leads to the generation of "best fit" offspring, which are likely to have a greater fitness with respect to their ancestors. Indeed, following the definition of proper reproduction and fitness functions, the evolution of a GA begins with the random generation of an initial population and then continues by looping over an iteration process to make that population progress. Notably, among the different GAs contained in the $\mathrm{mF}$ framework, the one called MOGA-II has been used in the optimization procedure of the suggested methodology. MOGA-II represents an improved version of MOGA (Multi-Objective Genetic Algorithm) which has been developed by Poloni and it is based on the concept of Pareto optimality. This notion identifies the feasible criterion space (i.e., the Pareto front) as the set of optimal points which represent trade-off solutions among the objectives of the problem at hand. Offering a wide range of options, the Pareto set proves to include optimal solutions from a comprehensive point of view and, thus, it allows decision makers to make a more informed final decision. As a matter of fact, the wide/systemic perspective employed in the generation of the Pareto front permits exploring the effects of decisions on the analyzed system with respect to all the considered objectives. In this regard, either before or after the investigation of acceptable solutions, further evaluation criteria can be introduced by decision makers to guide, refine or narrow the search for the preferred solution [29].

\section{Case Study}

The proposed methodology integrating modelling, simulation and optimization has been applied to the case study of the Port of Trieste, which is the first Italian port with respect to both the total annual throughput and the railway share for freight transfers to/from the hinterland. It is situated in the Northern Eastern part of Italy, in a strategic position in the heart of Europe, and it represents the crossroads of various maritime routes and transport corridors. Indeed, it constitutes an important international hub 
for the land-sea flows concerning the marketplaces of Central and Eastern Europe and, more lately, also of Far East. Thanks to its location along the Silk Road and to its great water depth, reaching up to $18 \mathrm{~m}$, in the latest years the Port of Trieste has recorded a significant increase in traffic volumes, which are expected to grow even further according to future macroeconomic tendencies. Moreover, it is characterized by the Free Port regime, which entails that customers can benefit from special regulations with respect to customs procedures and the fiscal regime [30]. Proof of this, a wall marks such different legal framework, physically separating the Free Port zone from the other surrounding port areas. However, in face of commercial advantages, in practical terms this condition implies more complex administrative procedures for the functioning of the port system, because it requires the engagement of a larger group of stakeholders to actually transfer freight. At infrastructural level, the Port of Trieste has available an internal railway network which is efficiently connected with the national and international ones. The development of intermodal transport in the Port of Trieste is sustained also by the presence of two of the nine TEN-T (Trans-European Transport Network) corridors in the territory of the Friuli Venezia Giulia region, which is the area it belongs to. The port does not serve the surrounding territory offering first-last mile services to local producers, since it constitutes an international hub for long-haul intermodal transport services in Europe. For this reason, issues related to the first-last mile problem, that are discussed for example in [31,32], do not concern the examined port. In this latter specific situation, interesting investigations can be performed with respect to the transfers of shunting locomotives between the main port railway station and the terminals which, in a broad sense, can be assumed as a sort of first-last mile connections.

Railway processes in the Port of Trieste have been modelled through the BMPN standard considering different aspects, namely both transport operations and the administrative procedures. As a matter of fact, referring to the exemplifying Figure 2 and to its portion reported in Figure 3, the developed models not only display the physical movements of trains and shunting locomotives during arrival and departure processes, but they also take into account the information flow needed to manage freight and train transfers in the port. In particular, even if Figure 2 is not so easily readable due to size constraints, it allows better understanding of the complexity of the modelled system, while the model extract included in Figure 3 enables to show process tasks and gateways according to the BPMN standard. The information necessary to build process models have been gathered, on one hand, by consulting the official documentation provided by the Port Authority and, on the other hand, during frequent technical meetings with the Railway Infrastructure Department. The gradual refinement of models has permitted an in-depth comprehension of the investigated railway operations and it has been made contextually to the definition of some assumptions regarding both the parametrization of modelled elements and the simulation functioning. 


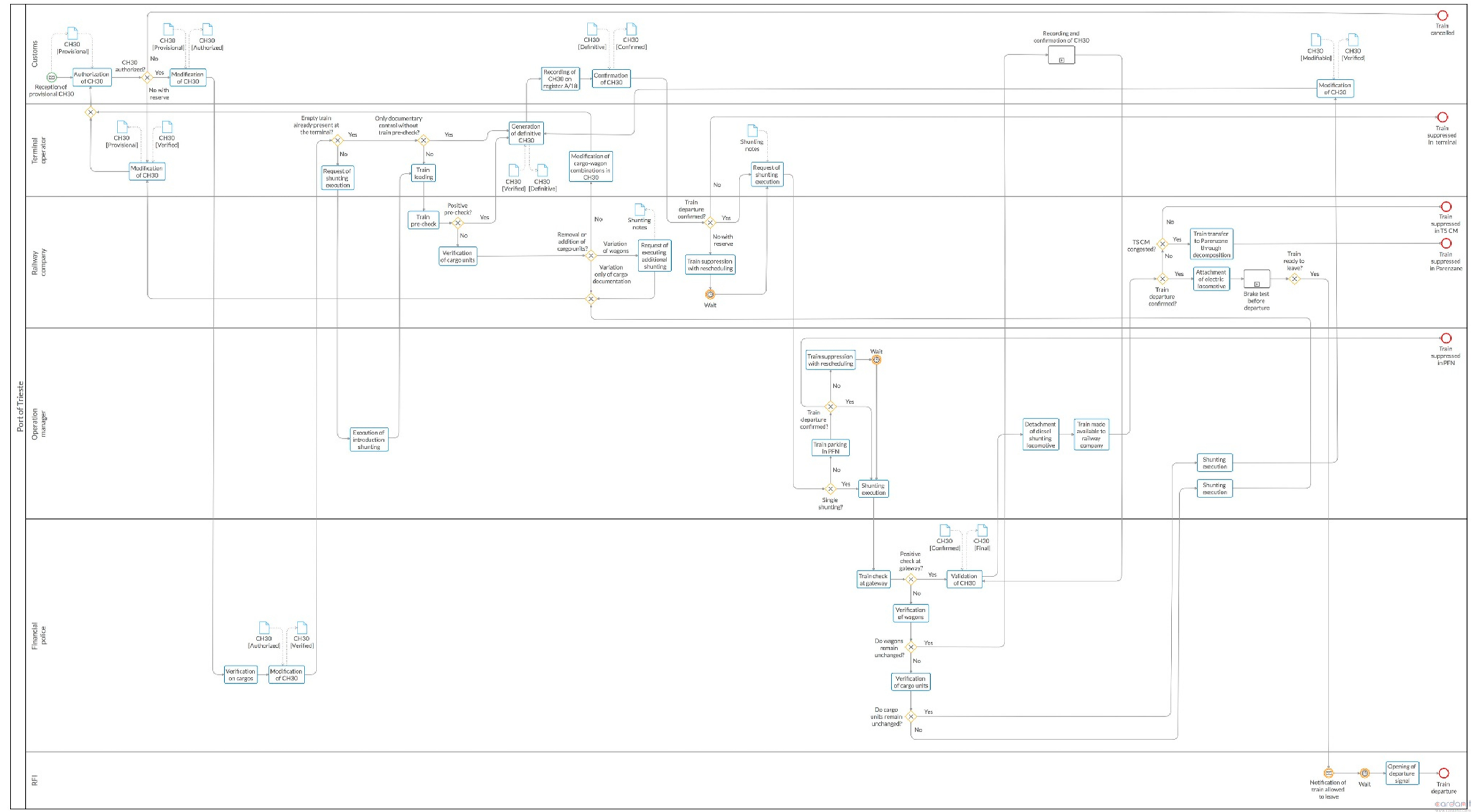

Figure 2. Developed BPMN model for railway processes. 


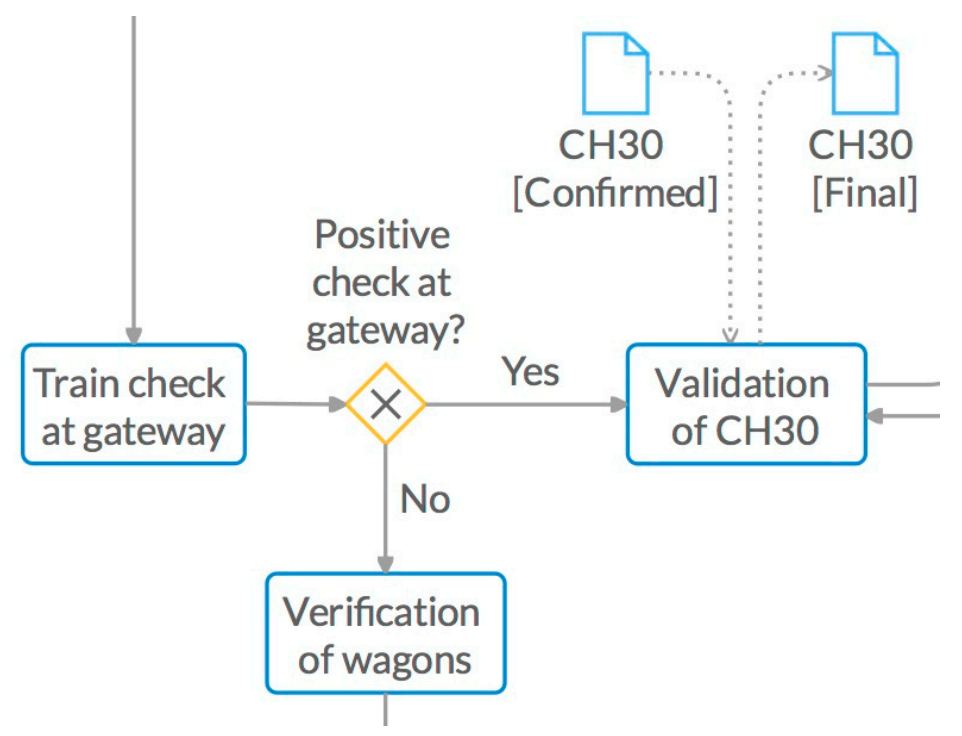

Figure 3. Portion of the developed BPMN models for railway processes.

The labelling of the elements displayed in the BPMN models, and concerning specifically railway operations, has been based on a schematization of the port railway network which refers to the current layout of the railway infrastructure of the commercial port. This representation has also served the parametrization phase of the models, suggesting clear reference to the various parts of the analyzed transport node. The schematization considers the following main components of the port network: the main station connecting the port network to the national one, different sets of tracks used to carry out shunting operations, the two gateways separating the Free Port zone from the external areas, and the three terminals present in that area of the Port of Trieste. In addition, some side but yet fundamental infrastructural resources have been taken into account and consist of the switches connecting with each other the abovementioned components, which allow the occurrence of train traffic. The developed overview of the port railway network has enabled also the identification of the itineraries that can be travelled by trains and, in particular, the necessary shunting operations to enter/exit them in/from the port. This task has highlighted the existence of conflicting points due to the availability of some limited infrastructural resources (i.e., single tracks), anticipating the presence of potential bottlenecks, that has been effectively proved by simulation runs at a later time. The parametrization phase has consisted in the setting of the characteristics of the simulation model elements, namely in relation to the duration of the simulation scenario (including a proper warm-up time), the generation and distribution of tokens, the quantity of operational and infrastructural resources, the duration of tasks, and the principles regulating process flows at decision points. For simulation purposes, some operational requirements have been determined for the management of resource, i.e., the occupancy of tracks and the use of shunting locomotives, in order to reflect the actual system operations. Furthermore, train arrivals and departures have been determined according to the potential residual capacity of the national railway network in different time slots, with reference to an average-traffic day. With respect to the capacity of the considered port area, exceeding trains have been overlooked and accounted for the estimation of possible traffic volumes in other parts of the Port of Trieste. Regarding queue management, the logic for ordering trains assumed in the simulation model considers that, just as in reality, priority is given to trains that respect the scheduled timetable. Therefore, in case of queues, these latter are prioritized over the others in the deployment of resources. Figure 4 illustrates the workflow developed by means of $\mathrm{mF}$ to perform the multi-objective optimization procedure: it can be noticed that input variables are reported at the top through green icons, output variables are displayed by the blue icons at the bottom and, finally, the integration node with the external simulator is reported in the middle. 


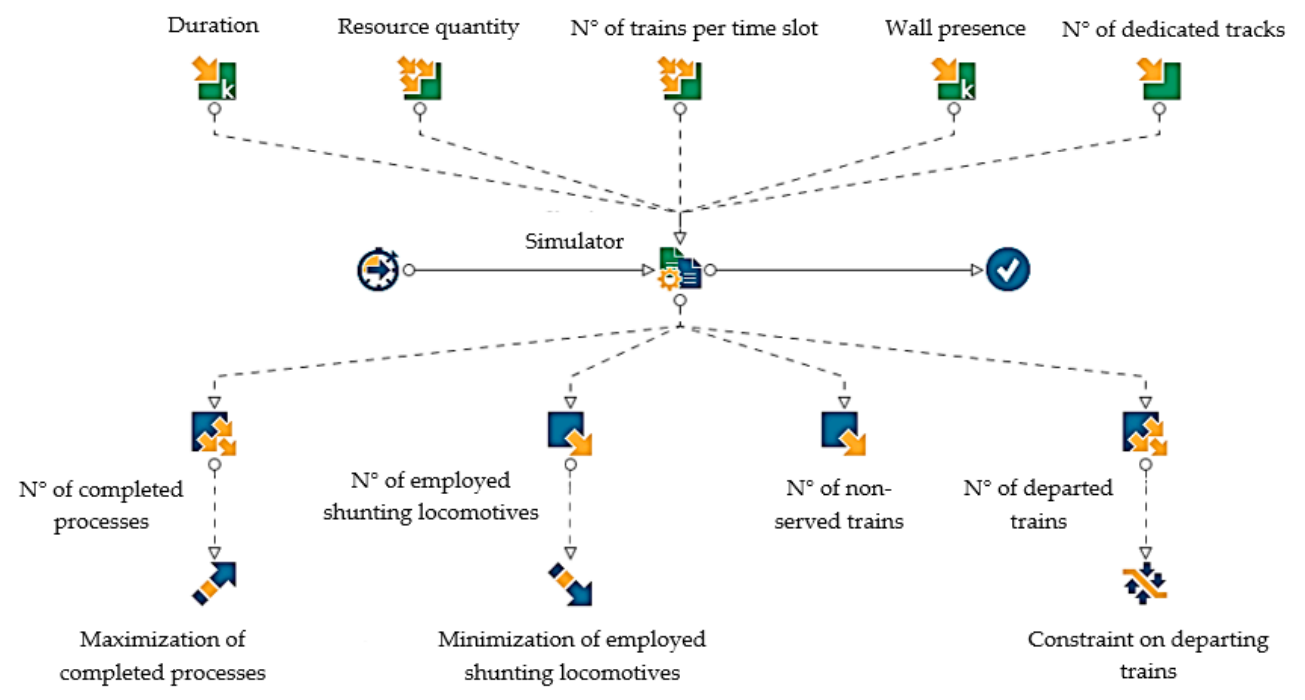

Figure 4. The $\mathrm{mF}$ workflow developed for the optimization procedure.

Input variables consists of the duration of the simulation scenario, the entity of infrastructural and operational resources, the number of train arrivals and departures in the different time slots, the presence or absence of the wall delimiting the Free Port zone, and the number of tracks dedicated to trains or shunting locomotives travelling in the opposite direction along the infrastructural components with multiple resources. Output variables correspond to both the objectives and the constraints defined in the procedure. As mentioned, the former include, on one hand, the maximization of the number of completed processes, i.e., the railway capacity and, on the other hand, the minimization of the number of shunting locomotives employed to perform train transfers. The latter refer only to the constraint imposed on the number of departed trains, which has limited based on the potential residual capacity of the national railway network in the various time slots. Lastly, an additional output variable has been introduced to account for the number of potential trains which cannot be served by the commercial port.

For each design of experiment, 1000 optimization runs have been performed using the MOGA-II algorithm and, according to the port development plan, the following changes have been considered, respectively, at infrastructural and operational level: a variation of the number of tracks available at the main station in a range from 8 to 12 and a reduction in the time duration of administrative tasks in correspondence of the two gateways delimiting the Free Port zone from the external areas, due to the expected demolition of the separating wall.

\section{Results and Discussion}

The Pareto front obtained applying the described optimization procedure is reported in Figure 5 and shows the possible trade-off solutions ensuring the maximization of port railway capacity along with the minimization of the number of shunting locomotives. More particularly, solutions represented in Figure 5 consider an additional dimension of analysis, i.e., tracks availability at the main port station, which is reflected by the different colors of the bubbles displayed in the chart.

On the contrary, no graphical optimization results are provided with regard to the impact of accelerating documentary tasks at gateways delimiting the Free Port zone, because no significant beneficial effects of such change on railway capacity have been recorded. 


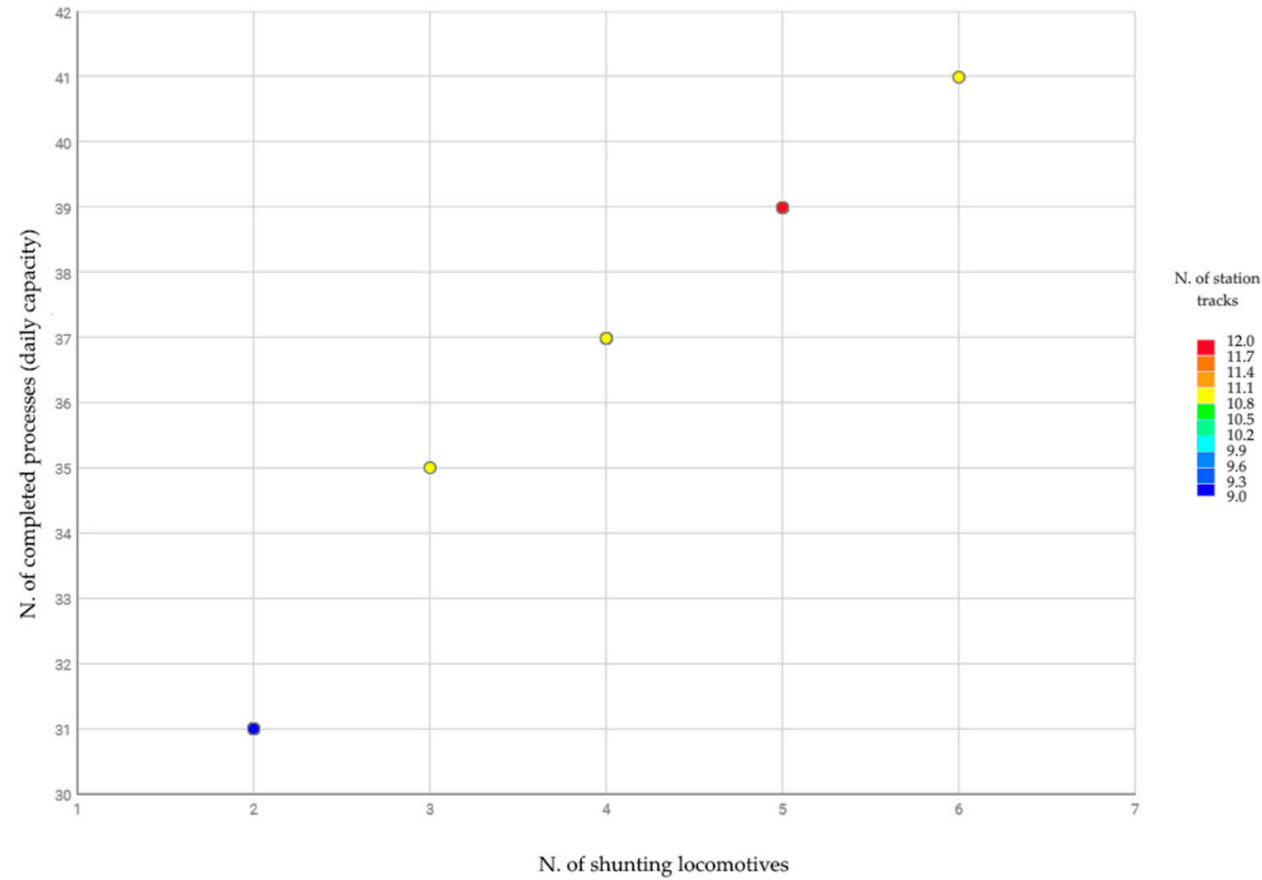

Figure 5. The Pareto front in relation to tracks availability at the main port station.

The results obtained by the multi-objective optimization procedure, discussed above, and indicating quite a linear relationship between the capacity increase and the number of shunting locomotives, gave insights for deeper investigations not only on the mutual influence of these two, but also on the potential contribution of further infrastructural components of the port railway network. To this end, a two-layer optimization procedure has been developed considering, on one hand, changes in the entity of employed locomotives and, on the other hand, in the amount of infrastructural resources of a certain shunting track collection. As illustrated in Figure 6, such articulation in computing the optimal capacity revealed that a significant rise of train flows is attainable until the number of used locomotives equals to five, which can be therefore assumed as a threshold value for the level of influence of those operational resources. As proof of this, it can be observed that a larger amount of shunting locomotives entails a decreasing marginal growth of railway traffic volumes.

The outcome regarding the effect of the number of locomotives on capacity is confirmed in Figure 7, which shows such dependence even in relation to an internal collection of tracks used for shunting operations. The entity of tracks availability in this latter is captured by the diverse dimension of the diameter size of the bubbles, while, similarly to Figure 3, the same parameter referred to the main port station is indicated through the various colors by which bubbles are filled in. The minor relevance covered by the analyzed collection of tracks is tested by the presence of bubbles with a quite small diameter also in correspondence to high values of railway capacity, and the fact that many of them are colored red again emphasizes the greater importance of tracks availability at the main port station. 


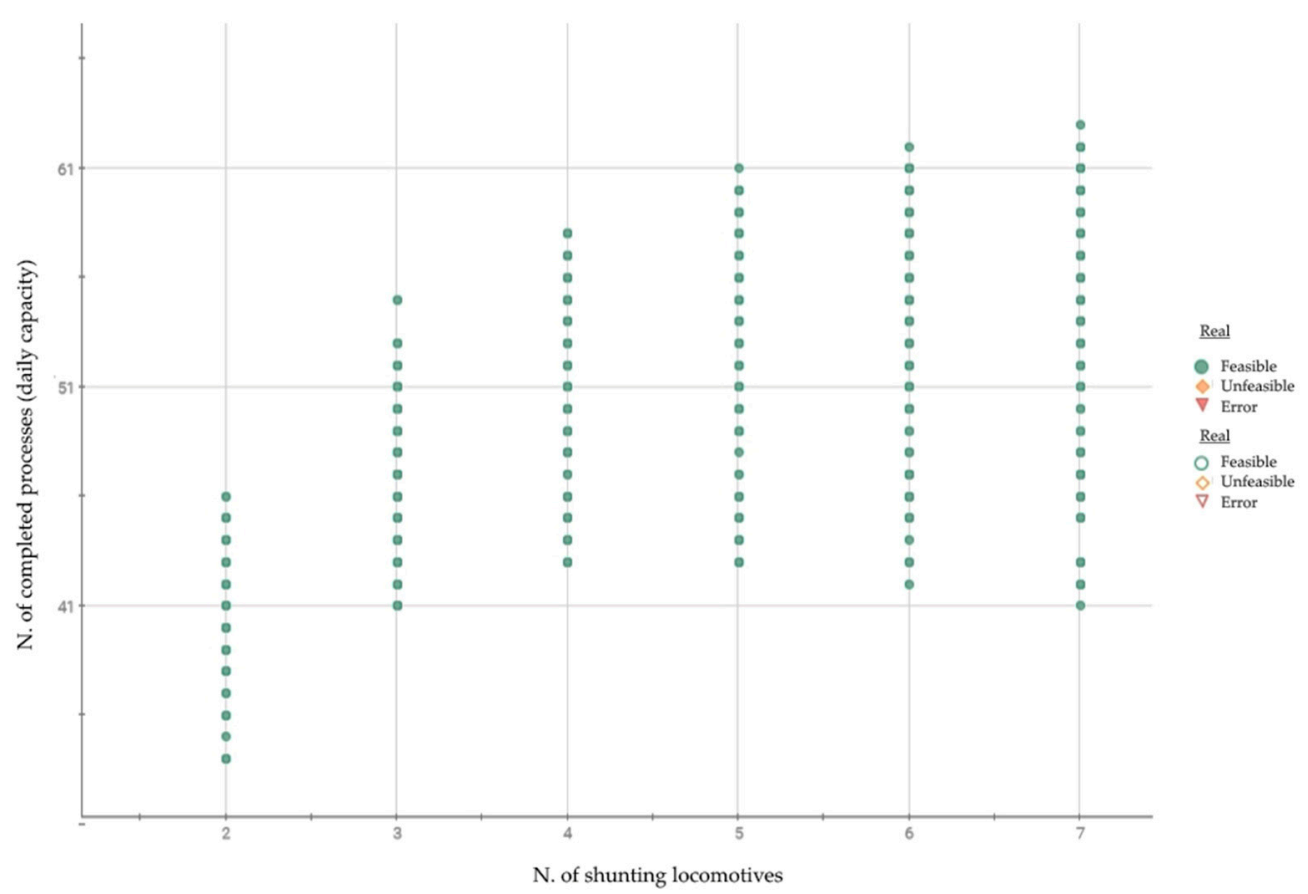

Figure 6. Results showing the threshold value for shunting locomotives.

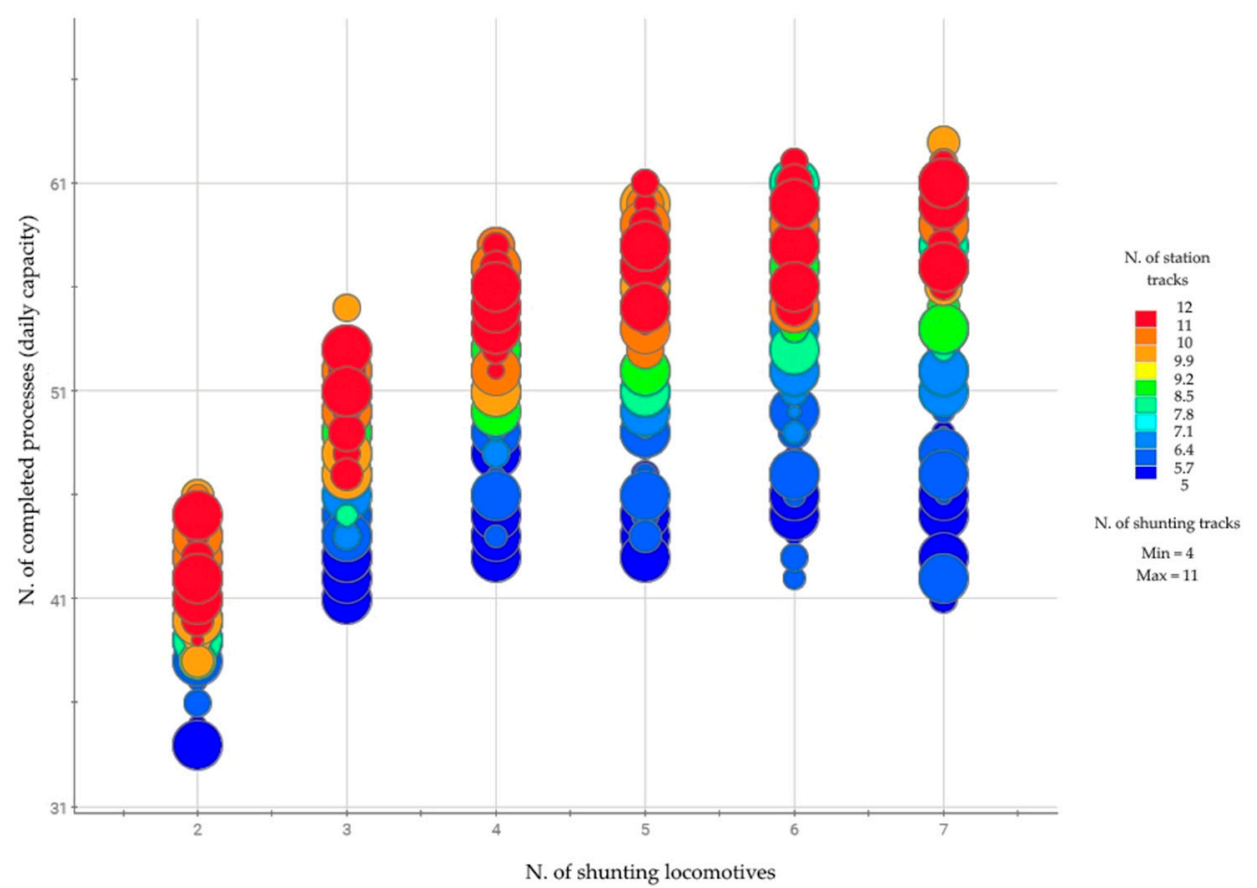

Figure 7. Results showing the influence of shunting locomotives, and of station and shunting tracks.

Results obtained by both the performed optimization procedure, and especially by the second one, definitely offer useful cues to port decision makers, since they suggest that, in line with the aim of increasing railway capacity, during the realization of port advancement works priority should be given to the availability of tracks at the main port station, rather than to the one of other collections of tracks and to the introduction of more locomotives for shunting operations. 


\section{Conclusions}

Driven by the need of accommodating future additional freight train flows in the complex context of seaports, a methodology for the estimation of the optimal railway capacity has been developed integrating modelling, simulation and optimization techniques, with the aim of formulating suggestions that can help port decision makers in selecting the best strategy. In more detail, the first stage of the proposed methodology consists in the representation of railway processes through a standardized modelling language, which facilitates the comprehension of processes. Prior to the actual simulation of processes, operational requirements are defined and the parametrization of modelled elements is performed. Railway processes are then simulated according to a discrete-event approach, allowing the identification of the main factors that hinder the execution of train transfers. Finally, an optimization procedure is carried out by means of a multi-objective framework to determine possible solutions for the maximization of train flows and the concurrent minimization of the number of employed shunting locomotives, to varying of critical infrastructural and operational conditions. The methodology has been applied to the case study of the Port of Trieste, Italy, for which results proved that tracks availability at the main port station covers a more influential role than the employment of a larger number of shunting locomotives in increasing traffic volumes. Moreover, no relevant beneficial consequences on railway capacity has been registered following a reduction in the time duration of documentary tasks at gateways delimiting the Free Port zone. Such results gave insights for the performing of a more articulated optimization procedure, in which changes in the amount of further infrastructural resources and of locomotives has been considered at two different level of analysis to better capture their relationship with capacity increases. This additional investigation revealed the identification of a threshold value for the impact of shunting locomotives and the poor influence of a specific collection of shunting tracks inside the port, while confirming the greater significance of tracks availability at the main port station. In practical terms, these outcomes can definitely contribute to support decision makers in defining an effective strategy to manage port advancement works. In this regard, the decision of selecting standardized techniques for the development methodology, such as BPMN, DES and GAs, has been made to intentionally foster the potential transferability of the suggested approach to further application contexts.

Future developments of the suggested optimization methodology consist of, on one hand, implementation of an alternative logic functioning to manage tasks, so as to simulate token processing at gateways in a more accurate way, and on the other hand, complementing BPMN with the Decision Model and Notation (DMN) standard [33] to model decision-making aspects in business processes, supporting stakeholders in the understanding and analysis of articulated domains by structuring business rules in the form of decision tables. Finally, at application level, the proposed methodology lends itself to be adopted not only for more extensive case studies, but also in applications concerning further transport-related aspects, as confirmed by some on-going research and practical activities by part of the authors.

Author Contributions: Conceptualization and methodology, C.C., G.L., T.M. and C.P.; software, T.M. and C.P.; investigation, C.C.; results analysis, C.C. and G.L.; writing - original draft preparation, C.C.; writing—review and editing, C.C.; visualization, T.M.; supervision, G.L. and C.P.; project administration, G.L. All authors have read and agreed to the published version of the manuscript.

Funding: This research received no external funding.

Institutional Review Board Statement: Not applicable.

Informed Consent Statement: Not applicable.

Conflicts of Interest: The authors declare no conflict of interest. 


\section{References}

1. Radhika, D. The New Role of Seaports as Integral Parts of Global Supply Chains. Int. J. Multidiscip. Manag. Stud. 2012, 2, 131-144.

2. Gaur, P. Port Planning as a Strategic Tool: A Typology. Master's Thesis, Institute of Transport and Maritime Management Antwerp, University of Antwerp, Antwerp, Belgium, April 2005.

3. Roh, H.S.; Lalwani, C.S.; Naim, M.M. Modelling a port logistics process using the structured analysis and design technique. Int. J. Logist. Res. Appl. 2007, 10, 283-302. [CrossRef]

4. van der Host, M.R.; van der Lugt, L.M. Coordination mechanisms in improving hinterland accessibility: Empirical analysis in the port of Rotterdam. Marit. Policy Manag. 2011, 38, 415-435. [CrossRef]

5. Samimi, A.; Kawamura, K.; Mohammadian, A. A behavioral analysis of freight mode choice decisions. Transp. Plan. Technol. 2011, 34, 857-869. [CrossRef]

6. Commission of the European Communities. Communication on a European Ports Policy; Commission of the European Communities: Brussels, Belgium, 2007.

7. Commission of the European Communities. Ports: An Engine for Growth; Commission of the European Communities: Brussels, Belgium, 2013.

8. Commission of the European Communities. White Paper-European Transport Policy for 2010: Time to Decide; Commission of the European Communities: Brussels, Belgium, 2001.

9. Ko, R.K.L.; Lee, S.S.G.; Lee, E.W. Business Process Management (BPM) standards: A survey. Bus. Process Manag. J. 2009, 15, 744-791. [CrossRef]

10. Chinosi, M.; Trombetta, A. BPMN: An introduction to the standard. Comput. Stand. Interfaces 2012, 34, 124-134. [CrossRef]

11. Corradini, F.; Ferrari, A.; Fornari, F.; Gnesi, S.; Polini, A.; Re, B.; Spagnolo, G.O. A Guidelines framework for understandable BPMN models. Data Knowl. Eng. 2018, 113, 129-154. [CrossRef]

12. Nedeliaková, E.; Panák, M.; Šipuš, D. Innovative Trends in Process-Oriented Quality Management within Railway Transport. Period. Polytech. Transp. Eng. 2017, 45, 84-89. [CrossRef]

13. Business Process Model and Notation Specification. Available online: https://www.omg.org/spec/BPMN/2.0.2 (accessed on 1 August 2020).

14. Cardanit. Available online: https://www.cardanit.com/ (accessed on 1 April 2021).

15. Elbert, R.; Pontow, H. Standardization and Integration of Information Flow along the Maritime Transport Chain; Darmstadt Technical University, Department of Business Administration, Economics and Law, Institute for Business Studies (BWL): Darmstadt, Germany, 2013.

16. Bisogno, M.; Nota, G.; Saccomanno, A.; Tommasetti, A. Improving the efficiency of Port Community Systems through integrated information flows of logistics processes. Int. J. Digit. Account. Res. 2015, 15, 1-31. [CrossRef]

17. Maidstone, R. Discrete Event Simulation, System Dynamics and Agent Based Simulation: Discussion and Comparison. System 2012, 1, 1-6.

18. Nevis, M.R. A Discrete-Event Simulation Model for Seaport Operations. Simulation 1998, 70, 213-223. [CrossRef]

19. Van der Aalst, W. Business process simulation survival guide. In Handbook on Business Process Management 1: Introduction, Methods, and Information Systems, 2nd ed.; Rosemann, M., vom Brocke, J., Eds.; Springer: Berlin, Germany, 2015; pp. $337-370$.

20. BPSim. Available online: https://www.bpsim.org/specifications/2.0/WFMC-BPSWG-2016-01.pdf (accessed on 2 September 2020).

21. L-Sim. Available online: https://www.lanner.com/en-gb/technology/l-sim-bpmn-simulation-engine.html (accessed on 15 September 2020).

22. Cimino, M.G.C.A.; Palumbo, F.; Vaglini, F.; Ferro, E.; Celandroni, N.; La Rosa, D. Evaluating the impact of smart technologies on harbor's logistics via BPMN modeling and simulation. Inf. Technol. Manag. 2017, 18, 223-239. [CrossRef]

23. Koniewski, R.; Dzielinski, A.; Amborski, K. Use of Petri Nets and Business Processes Management Notation in Modelling and Simulation of Multimodal Logistics Chains. In Proceedings of the 20th European Conference on Modeling and Simulation, Institute of Control and Industrial Electronics, Warsaw University of Technology, Bonn, Germany, 28-31 May 2006.

24. Cabanillas, C.; Baumgrass, A.; Mendling, J.; Rogetzer, P.; Bellovoda, B. Towards the Enhancement of Business Process Monitoring for Complex Logistics Chains. In International Conference on Business Process Management; Springer: Cham, Switherland, 2013; pp. 305-317.

25. Poloni, C.; Pediroda, V. GA coupled with computationally expensive simulations: Tools to improve efficiency. In Genetic Algorithms in Engineering and Computer Science; John Wiley \& Sons Ltd.: Chichester, UK, 1997; pp. 267-288.

26. Longo, G.; Montrone, T.; Poloni, C. A New Multi-objective SolutionApproach Using ModeFRONTIER and OpenTrack for Energy-Efficient Train Timetabling Problem. In Computation and Big Data for Transport; Diez, P., Neittaanmäki, P., Periaux, J., Tuovinen, T., Pons-Prats, J., Eds.; Springer: Cham, Switherland, 2020; Volume 54, pp. 103-119.

27. modeFRONTIER. Available online: https://www.esteco.com/modefrontier (accessed on 1 April 2021).

28. Holland, J.H. Adaptation in Natural and Artificial Systems; The University of Michigan Press: Cambridge, MA, USA, 1975.

29. Ngatchou, P.; Zarei, A.; El-Sharkawi, M.A. Pareto Multi Objective Optimization. In Proceedings of the 13th International Conference on, Intelligent Systems Application to Power Systems, Arlington, VA, USA, 6-10 November 2005 ; pp. 84-91.

30. The Free Port of Trieste. Available online: http://www.trieste-marine-terminal.com/en/free-port-trieste (accessed on 1 April 2021). 
31. Bruzzone, F.; Cavallaro, F.; Nocera, S. The integration of passenger and freight transport for first-last mile operations. Transp. Policy 2021, 100, 31-48. [CrossRef] [PubMed]

32. Caspersen, E.; Navrud, S. The sharing economy and consumer preferences for environmentally sustainable last mile deliveries. Transp. Res. D Transp. Environ. 2021, 95, 102863. [CrossRef]

33. Decision Model and Notation. Available online: https://www.omg.org/dmn/ (accessed on 1 April 2021). 